\title{
Covalent Immobilization of Lipase on Bacterial Cellulose Membrane and Nanocellulose
}

\author{
Juliano Brisola ${ }^{a}$ (D), Gabriel Jonathan Sousa Andrade ${ }^{a}$,Sabrina Alves de Oliveira, \\ Renato Marcio Ribeiro Viana ${ }^{b}$, Paula Cristina de Sousa Faria Tischer ${ }^{a}$, Cesar Augusto Tischer ${ }^{\text {* }}$ \\ ${ }^{a}$ Universidade Estadual de Londrina (UEL), Departamento de Bioquímica e Biotecnologia, 86051-980, \\ Londrina, PR, Brasil. \\ ${ }^{b}$ Universidade Tecnológica Federal do Paraná (UTFPR), Departamento Acadêmico de Química, 86036- \\ 370, Londrina, PR, Brasil.
}

Received: July 09, 2021; Revised: January 16, 2022; Accepted: February 01, 2022

\begin{abstract}
The cellulose from Komagataeibacter hansenii is synthesized as a thin film at the surface of glucose based media. Strong acid hydrolysis release sections of crystalline cellulose chains in nanometric scale that leads to persistent suspensions in water. The cellulose anhydro-glucose hydroxyls are suitable to receive functional groups as enzymes, and lipases have great economic value being a valuable model for protein immobilization. In this work both, the membrane of bacterial cellulose as well the nanocellulose produced trough acid hydrolysis, was functionalized with a lipase. The bacterial cellulose membranes were produced by Hestrin-Schramm medium, and nanocelluloses produced from the pristine material was characterized using techniques as ${ }^{13} \mathrm{C}$ solid state NMR and transmission electron microscopy (TEM). The pristine membranes and nanocellulose were functionalized with succinic acid as linker, then lipase was conjugated using EDC ( $N$-(3-Dimethylaminopropyl)- $N$ '-ethylcarbodiimide hydrochloride), and NHS ( $N$-Hydroxysuccinimide). The effectiveness of the chemical process was characterized, and the lipase activity were measured. The presence of the succinic acid and amide linkage, as well physicalchemical changes on the functionalized polysaccharide. Hence, we inferred that after immobilization the enzyme maintained its activity in both cellulose and the cellulose membrane.
\end{abstract}

Keywords: Biodegradable polymers; Industrial applications; Nanomaterials.

\section{Introduction}

The anhydrous-glucose is the representative monomer for the linear cellulose chain, is constituted of two $\beta-(1 \rightarrow 4)$ linked glucose molecules, each rotated $180^{\circ}$ relative to the neighboring molecule $\mathrm{e}^{1,2}$. Cellulose has interesting properties including biodegradability, relative chemical inertia, high temperature, and mechanical strength.

The bacteria Komagataeibacter hanseni, is able to produce cellulose, structurally similar to plant cellulose free of other intrinsically blended polymers like plant hemicelluloses and polyphenols. Furthermore, the fibrils are smaller and the cellulose is more crystalline than those $\mathrm{e}^{3-5}$.

Cellulose polysaccharide is synthetized on cell membrane, then packs on crystalline domains surrounded by paracrystalline chains and interleaved by amorphous regions. The isolated ordered cellulose, formerly called cellulose whiskers, nowadays nanocellulose, or CNC, can be obtained on laboratory using sulfuric acid $(30 \%$ to $60 \%)$ at mild temperature $\left(45^{\circ} \mathrm{C}\right)$, a process that hydrolysates the amorphous regions, leaving high ordered fibers that are resistant to the acidic attack due to their high structural organization. These structures presents 2 to $20 \mathrm{~nm}$ in diameter and range from 100 to

*e-mail: cesar.tischer@me.com
$500 \mathrm{~nm}$ length, leading to an aspect ratio that varies according to the source of ${ }^{5-10}$.

Cellulose is affordable, stable, resistant to mechanical force, biocompatible and chemically inert ${ }^{11,12}$, skills that are expected for matrices to enzyme immobilization ${ }^{13}$. Nanocelluloses adopt a stacking distribution on polar solvents as water that trap on its 3D structures the enzyme subtracts. Being functional group attachment points, chain surface hydroxyls are more available to react, besides the heterogeneous reaction medium and the low reactivity of hydroxyl as a nucleophile ${ }^{14}$.

Lipases are enzymes belonging to the triacylglycerol acyl hydrolase family (EC 3.1.1.3), that operates with both the hydrolytic way and esterification catalysis, being used on a wide range of processes including hydrolysis, alkanolysis, acidolysis, amylolysis, and interesterification. This versatility opens its research to use or effectively applied in several industries, such as food, detergents, cosmetics, chemical, biomedical, and biodiesel industry ${ }^{15,16}$.

So many studies report that lipases com be physically immobilized, in which the enzyme is adsorbed on the support surface or network ${ }^{17-20}$. Enzyme immobilization had made laboratory and even industrial catalysis a more reliable processes, for example, due to the relative high cost to recovery these proteins from processed broth ${ }^{21}$. Enzymes 
are trapped inside 3D matrixes or attached chemically to the carrier trough covalent linkage, and the extracts are absorbed or distributed around the scaffold.

Cellulose is a carrier for proteins bonded to the hydroxyls widely distributed, directly linked or using intermediary molecules with organic functional groups. Ribeiro-Viana and cols $^{22}$. had functionalized bacterial cellulose with succinic acid as spacer and its carboxylic group gives the point to bind collagen conserving the original membrane morphology and the crystallinity, to use it as a new wound care material. Covalently linked bacterial celluloses with enzymes have shown joined attributes: biocompatibility, low toxicity as carrier and catalytic effectiveness for many kinds of selective processes $^{23,24}$. The high crystalline nanocelluloses, produced trough acid hydrolysis, remains in suspension for long time in water and other polar solvents, as result of the stacking of its mesophases ${ }^{25}$, that leads to a relevant characteristic to the coupled enzyme, that remains stable for a long time in suspension.

For these reasons in this study lipase was used as model for a covalently linked enzyme to-nanocellulose material, then characterize it structurally and as a functional macromolecule.

\section{Experimental Part}

\subsection{Materials}

The pyridine and dimethylformamide was dried in molecular sieve ( $3 \AA$ ) for $48 \mathrm{~h}$. The lipase used was lipase from commercial source (Lipolase 100L, batch LAP40080), kindly donated by Novozymes Latin America (Araucária, Paraná, Brazil). The bacteria used in this study was Komagataeibacter hansenii ATCC23769, obtained from the André Tosello Foundation, Campinas, São Paulo. $K$. hansenii was grown in culture medium containing 4\% glucose, based on Hestrin-Scharamm's medium ${ }^{26}$, and stored at $-80{ }^{\circ} \mathrm{C}$ in glycerol.

\subsection{Bacterial cellulose production}

The bacterial cellulose membranes (BC), was produced, inoculating $10 \%$ (v/v) of pre-inoculum in modified HestrinSchramm medium ${ }^{26}$, which was then mixed and aliquoted into polypropylene bottles. Production was kept static for 10 days, at $28{ }^{\circ} \mathrm{C}$, then the membranes on liquid surface were picked out, washed in water, and rinsed with $2 \%$ $\mathrm{NaOH}(\mathrm{w} / \mathrm{v})$ within $24 \mathrm{~h}$. then washed with water several times and adjusted to $\mathrm{pH} 7$.

\subsection{Nanocellulose production}

Nanocellulose, named NCB, were produced using acid hydrolysis. The cellulose membrane was dried until constant weight, then small discs were perforated into it, using a hole punch (5.5 $\mathrm{mm}$ diameter), and they were transferred to a flat-bottomed flask. Sulfuric acid, 34\% (v/v), was added to the cellulose discs, at a ratio of $30 \mathrm{~mL}$ to each $0.5 \mathrm{~g}$ of dry membrane. Following this, the material was neutralized with $25 \% \mathrm{NaOH}$ and dialyzed in bags $(25 \times 16 \mathrm{~mm}, 25 \AA)$ for 5 days. After dialysis, the material was frozen and lyophilized in conical tubes.

\subsection{Chemical reactions}

\subsubsection{Anhydride succinic preparation}

Succinic anhydride was synthesized as described by Ribeiro-Viana, Faria-Tischer, \& Tischer, 2016 ${ }^{22}$. Succinic acid $(4 \mathrm{~g})$ and acetic anhydride $(6.4 \mathrm{~mL})$ were combined in a round bottom flask, under reflux. The reaction occurred at $100{ }^{\circ} \mathrm{C}$ for one hour. After the reaction, the mixture was allowed to stand for two hours at room temperature, and then placed at $8{ }^{\circ} \mathrm{C}$ for $30 \mathrm{~min}$. The precipitate formed was washed with diethyl ether repeatedly, and then stored in a vacuum desiccator.

\subsubsection{Succinylation reaction of cellulose membranes and nanocellulose}

The succinylation reaction was performed according to the method described by Ribeiro-Viana; Faria-Tischer; Tischer, 2016 $6^{22}$. The bacterial cellulose membranes (BC) and nanocelluloses (NCB) were prewashed sequentially with methanol and dichloromethane to remove water. The pristine celluloses were immersed in dichloromethane on a round-bottomed flask with a pyridine and succinic anhydride; the ratio was $40 \mathrm{~mol}$ of anhydride per mol of cellulose, refluxed for $24 \mathrm{~h}$ at $70{ }^{\circ} \mathrm{C}$. The product obtained was washed first three times with distilled water, followed by $3 \mathrm{x}$ ethanol. Thereafter, the succinilated celluloses were dried at room temperature and so-called MB-s membranes and NCB-s for the nanocellulose powder.

\subsubsection{Immobilization of lipase in bacterial cellulose and nanocellulose}

The lipase was covalently linked to the succinilated celluloses trough free amino acid amines stirring both on water with EDC ( $N$-(3-Dimethylaminopropyl)- $N{ }^{\prime}$ ethylcarbodiimide hydrochloride), followed by the addition of NHS ( $N$-Hydroxysuccinimide) at stoichiometric ratio of $0.08 \mathrm{~mol}$ of protein per mol of cellulose/EDC/NHS in order to get the amide linkage ${ }^{22}$. In a round-bottomed flask MB-s and NCB-s were gently stirred for one hour at room temperature, then lipase was added keeping it shaking for $21 \mathrm{~h}$. After this, the product of the reaction was washed three times with distilled water and dried at room temperature in a vacuum desiccator. Thus, the functionalized membrane was named BC-lip and the nanocellulose as NCB-lip.

\subsection{Analytical methods}

\subsubsection{Solid state nuclear magnetic resonance - CP MAS NMR}

NMR to obtain the ${ }^{13} \mathrm{C}$ spectra of membranes or nanocellulose modified or not, was carried out and analyzed using a Bruker model Avance $400 \mathrm{MHz}$ equipment, operating at $100.6 \mathrm{MHz}$ for ${ }^{13} \mathrm{C}$, and using the magical angle crosspolarization technique (MAS) with cross polarization pulse. The crystallinity index $\left(\mathrm{I}_{c}\right)$ of cellulose membranes and nanocellulose was calculated using Equation 1, I is the integration value of the $\mathrm{C} 4$ crystalline signal and $\mathrm{I}_{\mathrm{a}}$ is the integration value of the amorphous $\mathrm{C} 4$. The spectra were analyzed using SpinWorks 4 software. 
$I_{C}=\frac{I}{I_{a}+I} \times 100$

\subsubsection{Infrared spectroscopy - FTIR}

The infrared spectra (FTIR) were obtained using a Shimadzu FTIR-8300, with a resolution of $4 \mathrm{~cm}^{-1}$ in the range of 4000 to $400 \mathrm{~cm}^{1}$, in transmittance mode. Modified or not cellulose samples were dried at $70{ }^{\circ} \mathrm{C}$ until constant weight before preparing them as pressed discs mixing $5 \mathrm{mg}$ of celluloses with $\mathrm{KBr}$.

\subsubsection{Thermogravimetric Analysis - TGA}

The celluloses thermal degradation profiles were characterized on a Shimadzu Thermogravimetric Analyzer model TGA-50. Samples, $\sim 5 \mathrm{mg}$, were analyzed in aluminum plates on a range from $25^{\circ} \mathrm{C}$ to $800{ }^{\circ} \mathrm{C}$, with a heating rate of $10{ }^{\circ} \mathrm{C} \mathrm{min}^{-1}$ in $\mathrm{N}_{2}$ atmosphere, at a rate of $50 \mathrm{~mL} \mathrm{~min}^{-1}$.

\subsubsection{X-ray diffraction - XRD}

All samples were analyzed with a Panalytical model X'PERT PRO MPD ( $\theta-2 \theta)$ X-ray diffraction equipment. A monochromatic incident beam of $\mathrm{Cu}$ (K2) was used at $40 \mathrm{KV}$ and $30 \mathrm{~mA}$. The diffractogram was generated from 5 to $60^{\circ}(2 \theta)$ and the scanning rate was $0.002^{\circ} / \mathrm{s}$.

\subsubsection{Determination of stability in the suspension of pristine, succinylated and lipase-immobilized nanocelluloses}

Samples of NCB, NCB-Suc and NCB-Lip, all at $1 \mathrm{mg} \mathrm{mL}^{-1}$ in water, were sonicated on ultrasonic bath for $80 \mathrm{~min}$. Each sample was divided into two flasks with $5 \mathrm{~mL}$ each. One was photographed at time intervals of $0,1,3,6$, 24 and 144 hours; the other aliquot was placed in a quartz cuvette and its absorbance was measured at the same time intervals. Before the absorbance measurement the sample was scanned, and the higher value was the same all the time, $270 \mathrm{~nm}$. The equipment used was the Jenway $6850 \mathrm{UV} / \mathrm{Vis}$ dual-beam scanning spectrophotometer.

\subsubsection{Transmission electron microscopy and measurement of nanoparticle sizes}

Nanocellulose samples were prepared at a concentration of $0.1 \mathrm{mg} \mathrm{mL}^{-1}$ and sonicated for 5 minutes. Subsequently 1 drop of the sample was deposited on the copper grid with Formvar (400 mesh - Ted Pella) film; after 10 minutes, another drop was deposited and the contrast was later obtained by negative staining with uranyl acetate. The samples were stored to dry, and the analyses were carried out in the Laboratory of Electron Microscopy and Microanalysis, UEL (LMEM), using the Jeol JEM 1200EX-II transmission microscope.

Particle sizes were measured using the software ImageJ; the scale bar was used to calibrate dimensions on photomicrographs, and the length and diameter of nanoparticles were plotted as histograms on Origin 8.

\subsubsection{Determination of lipase activity by ${ }^{1} H N M R$}

Immobilized lipase activity was determined by the ratio of free fatty acid signals obtained from ${ }^{1} \mathrm{H}$ NMR spectra compared with an unmodified sunflower oil control, according to the methodology proposed by Silva and cols ${ }^{27}$. The control sample, $1 \mathrm{ml}$ sunflower oil, was added to $1 \mathrm{~mL}$ distilled water and $20 \mu \mathrm{L}$ lipase (Lipolase $1001 \AA$, Novozymes). This was called the "Flip" sample. In order to measure the immobilized enzyme activity, $20 \mathrm{mg}$ lipase linked to the cellulose-membrane (BC-lip) and nanocellulose (NCBlip). Blank samples of succinylated membranes (BC-s) and nanocellulose (NCB-s) were mixed with Sunflower oil and the system was placed on a shaker table at $200 \mathrm{rpm}$ for 3 days at room temperature. After the reaction, the supernatant was collected and analyzed by ${ }^{1} \mathrm{H}$ NMR. Free fatty acids were quantified from the values of the integration of the $\alpha$-carbonyl methylene hydrogen peaks, 4.32 to $4.1 \mathrm{ppm}$, counted as 6 (equation 2), and its ratio to $\mathrm{C} 1$ and $\mathrm{C} 3$. The $-\mathrm{CH}_{2}-\mathrm{O}$ - group of glycerol was counted as four hydrogens.

$\frac{\% T G}{F F A}=\frac{\text { peak area methylene } \times 100}{4}$

The ${ }^{1} \mathrm{H}$ NMR spectra was obtained using a Bruker Avance III $400 \mathrm{MHz}$ spectrometer at the UEL Multiuser Research Center (RMN UEL - CMLP), on a $5 \mathrm{~mm}$ inverse probe. Quantitatively, $100 \mu \mathrm{L}$ of the reactive media was placed in $5 \mathrm{~mm}$ NMR tubes, containing $500 \mu \mathrm{L} \mathrm{CDCl}_{3}$. Chemical shifts were expressed in ppm and calibrated according to the TMS signal on the doped $\mathrm{CDCl}_{3}(\delta=0.000 \mathrm{ppm})$ used to dissolve the samples.

\subsubsection{Quantitation of the immobilized protein}

In order to determine the amount of protein linked to the celluloses, the method proposed by Atacan, $2016^{28}$ was used, where $5 \mu \mathrm{L}$ of Trypsin $\left(21.91 \mu \mathrm{g} \mathrm{mL} \mathrm{m}^{1}\right)$ was added to $20 \mathrm{mg}$ of pristine and modified celluloses, followed by addition of $495 \mu \mathrm{L}$ of phosphate buffer $(\mathrm{pH} 8)$ and $0.2 \mathrm{M}\left(\mathrm{Na}_{2} \mathrm{HPO}_{3} /\right.$ $\mathrm{NaH}_{2} \mathrm{PO}_{3}$ ). The system was incubated at $37^{\circ} \mathrm{C}$ for $13 \mathrm{~h}$ under static conditions. After the reaction, the protein concentration was determined using Bradford assay ${ }^{29}$.

\section{Results and Discussion}

The first step to immobilizing the enzyme was to link the succinate linker to both celluloses: membrane, and nanocelluloses. The process we chose for this conserves the macroscopic morphology it means that.

On comparing the FTIR data between native cellulose membrane $(\mathrm{BC})$ and cellulose membrane functionalized with succinic acid (BC-s) (Figure 1A), we observed the appearance of the band at $1727 \mathrm{~cm}^{-1}$ on the succinylated membrane, for the $\mathrm{C}=\mathrm{O}_{\text {bond }}{ }^{30}$. In all the analyzed materials, an absorption band was observed at $3360 \mathrm{~cm}^{-1}$, responsible for the vibration of the $\mathrm{OH}$ stretch, while the absorption band at $2894 \mathrm{~cm}^{-1}$ was due to the $\mathrm{CH}$ stretch $^{31}$. In the membrane (BC-lip) and lipase-immobilized nanocellulose NBC-lip, a new band was observed at $1640 \mathrm{~cm}^{-1}$, responsible for the amine group derived from lipase amino acid residues.

The FTIR spectra of nanocellulose, Figure 1B, showed absorption bands similar to the membrane spectrum. NCBsuc had an intense band at $1739 \mathrm{~cm}^{-1}$ from the ester-bond stretching vibration, high absorption at $3419 \mathrm{~cm}^{-1}$ from the vibration of the $\mathrm{OH}$ stretch, and an absorption at $2885 \mathrm{~cm}^{-1}$ from the $\mathrm{CH}$ linkage. 

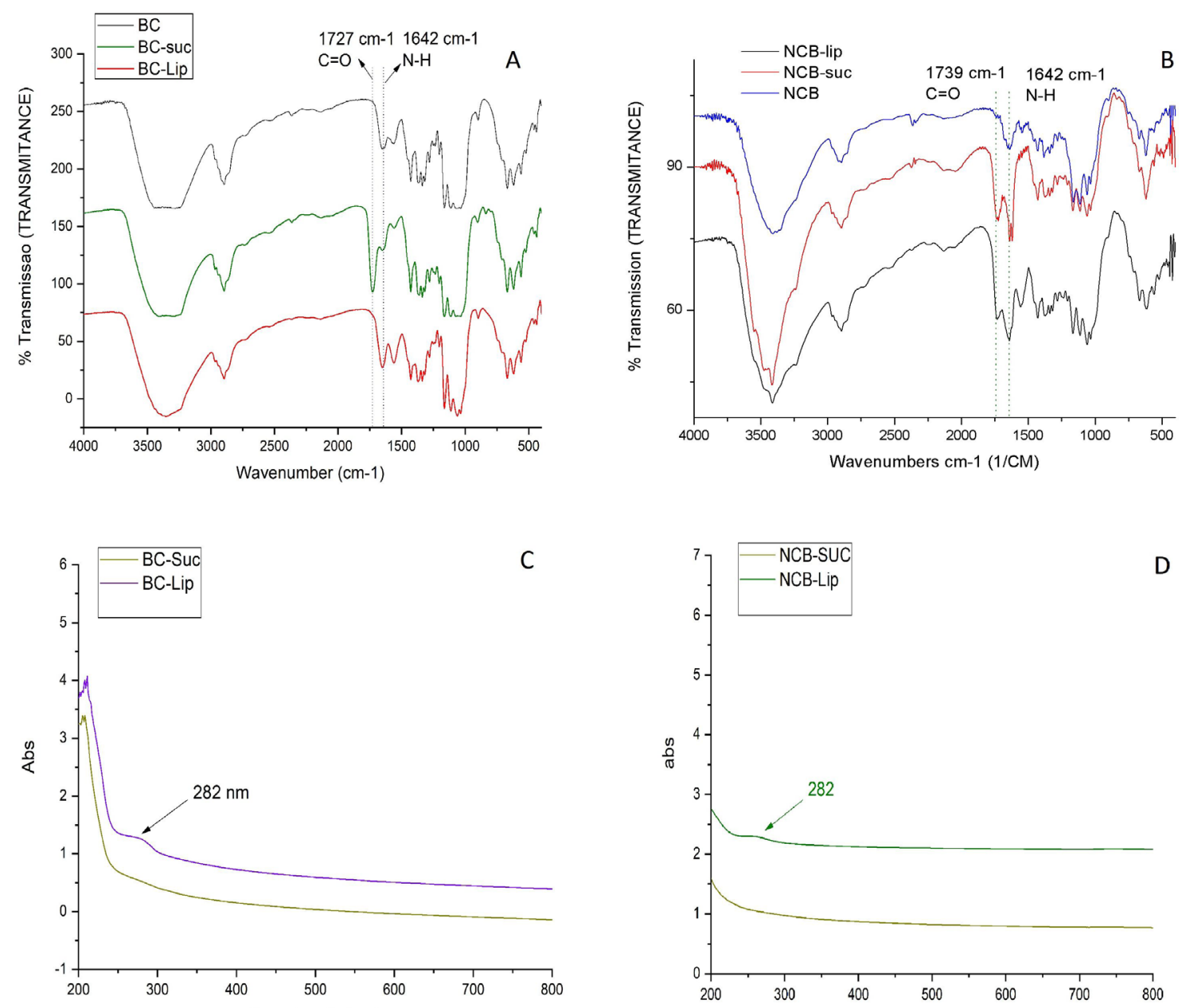

Figure 1. (A) Infrared Spectrum (FTIR) of native cellulose membrane BC, succinylated BC-suc and immobilized Lipase BC-lip. (B): Infrared Spectrum (FTIR) of succinylated nanocellulose. (C) UV-vis Spectrum of succinylated membrane and immobilized lipase. (D) UV-Vis Spectrum of succinylated nanocellulose and immobilized lipase.

The solid state ${ }^{13} \mathrm{C}$ NMR spectra of celluloses membrane and nanocellulose, Figure 2 and 3, shown all anhydro-glucoses for $\mathrm{C} 1$ at $102-108 \mathrm{ppm}$, and the signals between $81-93 \mathrm{ppm}$ that corresponds to $\mathrm{C} 4$, where the signal is centered at $89 \mathrm{ppm}$ to carbons in crystalline arrangements and at $85 \mathrm{ppm}$ those that aren't involved with regular hydrogen linkages, the amorphous or paracrystalline chains. Signals that showed resonances between $62-66 \mathrm{ppm}$ assigned as $\mathrm{C} 6$ carbons, The signals between 70-75 ppm corresponds to $\mathrm{C} 2, \mathrm{C} 3, \mathrm{C} 5^{22,31,32}$.

The solid state $\mathrm{nmr}$ spectra for BC-suc and NCB-suc shows signals at $32 \mathrm{ppm}$ for $-\mathrm{CH}_{2}$ - and $\sim 174 \mathrm{ppm}$ for carbonyl group; on the BC-lip and NCB-lip the wide range of signals characteristic for protein $\mathrm{nmr}$ spectra can be seen.

The chemical process to produce nanocellulose is well known and not surprisingly, the morphology of the acid hydrolysis product studied by transmission electron microscopy (Figure 4), showed the typical straight whiskers, widely described in literature, and the small needle shaped nanofibrils could be identified. The succinylation reaction, followed by the conjugation with lipase, did not change the morphology and particle size distribution of nanocellulose as

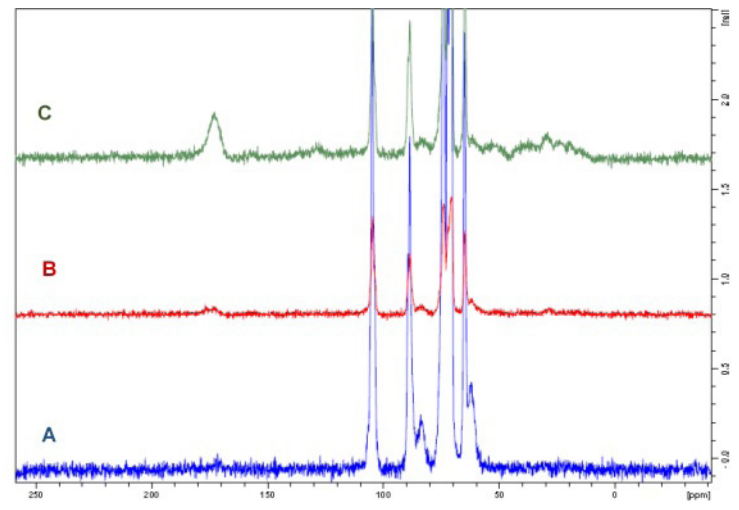

Figure 2. Solid state ${ }^{13} \mathrm{C} n m r$ spectra of nanocellulose. (A) Pristine $\mathrm{NCB}$; (B) with succinic acid, NCB-suc; (C) conjugated with lipase, NCB-lip.

shown in Figure 5. NCB and NCB-suc has average diameters of $30-40 \mathrm{~nm}$ and average lengths of $300-400 \mathrm{~nm}$ giving an aspect ratio of $\sim 13$. This results in shape, size and aspect ratio agree with what was found by other authors ${ }^{33-35}$. 
The TGA curves of $\mathrm{BC}$, native, succinylated and immobilized lipase, and pristine, succinylated and lipase immobilized NCBs are shown in Figure 6. The three membranes shown different degradation profiles. The first stage of degradation was responsible for water loss, about $2.67 \%$ at $49.2^{\circ} \mathrm{C}$ for the $\mathrm{BC}, 11.09 \%$ at $48.63^{\circ} \mathrm{C}$ in the $\mathrm{BC}$-suc, and $6.68 \%$ at $55.24^{\circ} \mathrm{C}$ for the BC-lip membrane. The loss of mass of $53.59 \%$ was observed for $\mathrm{BC}$ at $253.16^{\circ} \mathrm{C}$, then $49,16 \%$ at $259,17^{\circ} \mathrm{C}$ for $\mathrm{BC}$-suc, and $50.38 \%$ at $269.83^{\circ} \mathrm{C}$ $\mathrm{BC}$-lip. Comparing the $\mathrm{BC}$ with $\mathrm{BC}$-suc membrane, the

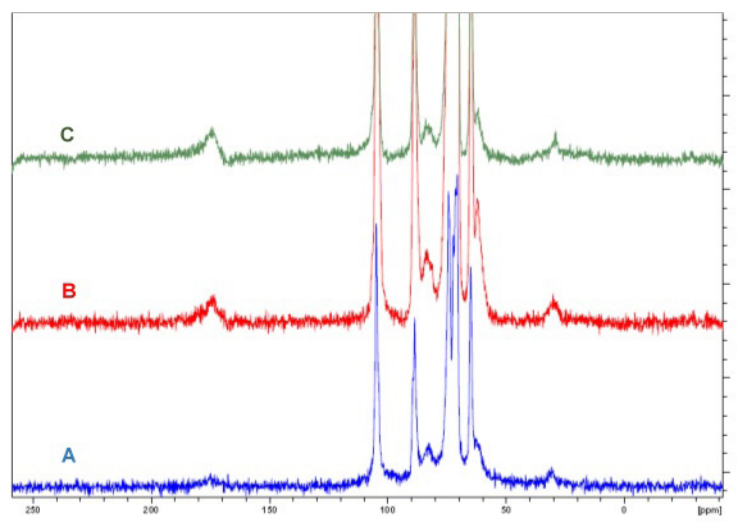

Figure 3. ${ }^{13} \mathrm{C}$ NMR spectra of $\mathrm{BC}$ membranes (A); with succinic acid $\mathrm{BC}$-suc (B); and functionalyzed with lipase, BC-lip. conjugated (C). addition of the succinic group conferred a higher stability. The TGA graphs for pristine, succinylated and lipaseimmobilized NCBs presented changes on its degradation profiles. The water loss occurred at $49,56{ }^{\circ} \mathrm{C}$ for all, cutting $13.95 \%$ of NCB mass, $9.45 \%$ of the NCB-suc and $15.78 \%$ of NCB-lip. The degradation and most significant loss of mass for NCB, NCB-suc and NCB-lip occurred at $252,42^{\circ} \mathrm{C}$ (mass loss: $58.18 \%), 258,28^{\circ} \mathrm{C}(55.64 \%)$, and $278,53^{\circ} \mathrm{C}$ (58.18\%), respectively. As with the membranes, when the nanocellulose was functionalized with succinic acid, an increase in thermal stability was observed in relation to the pristine nanocellulose, and in the immobilization of lipase in the nanocellulose, there was an even greater increase in thermal stability.

The diffraction patterns of celluloses as membrane are shown on Figure 7. We observed three characteristic peaks at $14.6^{\circ}, 16.8^{\circ}$ and $22.6^{\circ}$, and these were related to the $(1,-1,0),(1,1,0)$ and $(2,0,0)$ indices demonstrated to be type I cellulose and nanocellulose

The crystallinity index of the nanocellulose was also verified by the XRD technique, and were $70 \%, 83 \%$ and $70 \%$, respectively for NCB, NCB-suc and NCB-lip. For the native membrane $\mathrm{BC}$, functionalized with succinic acid and lipase were $76 \%$ (BC), 42\% (BC-suc) and 80\% (BC-lip). Comparing them we observed that the nanocellulose contains a higher crystallinity ${ }^{36}$.
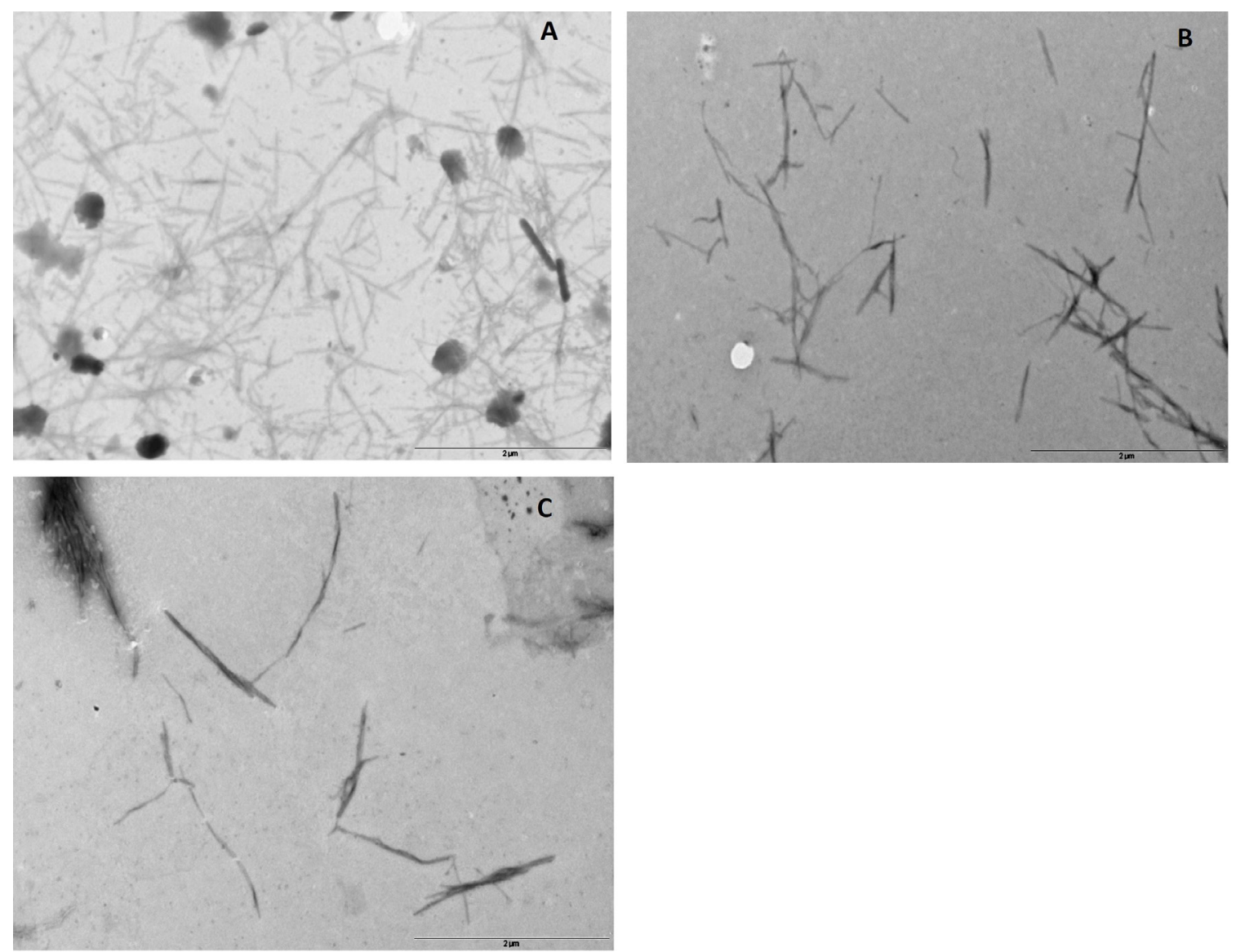

Figure 4. TEM images of pristine nanocellulose NCB (A), succinated (NCB-suc, B), and NCB-lip for conjugated with lipase (C). 

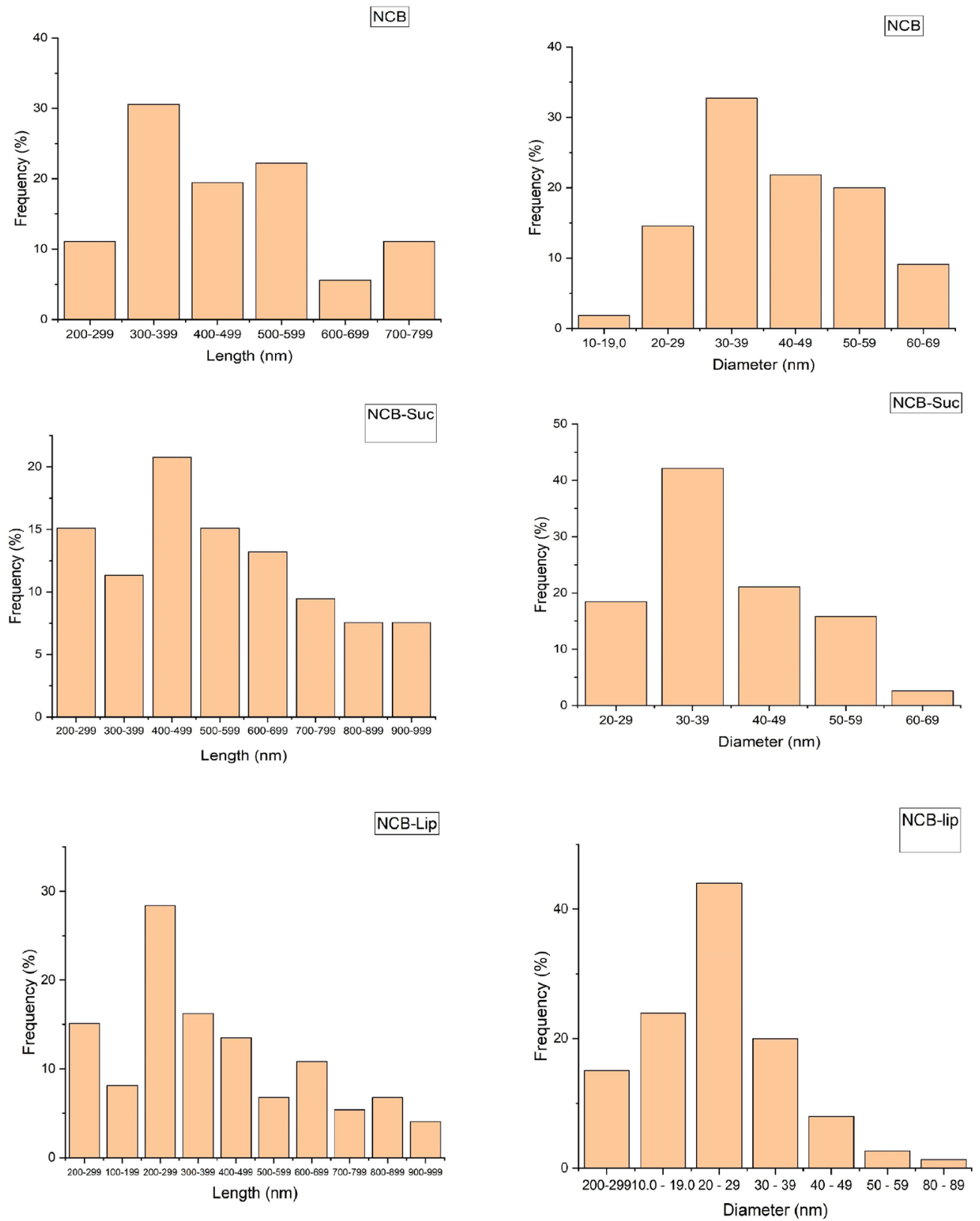

Figure 5. Distribution of the diameter and length of the pristine, succinylated, and lipase-conjugated NCBs.
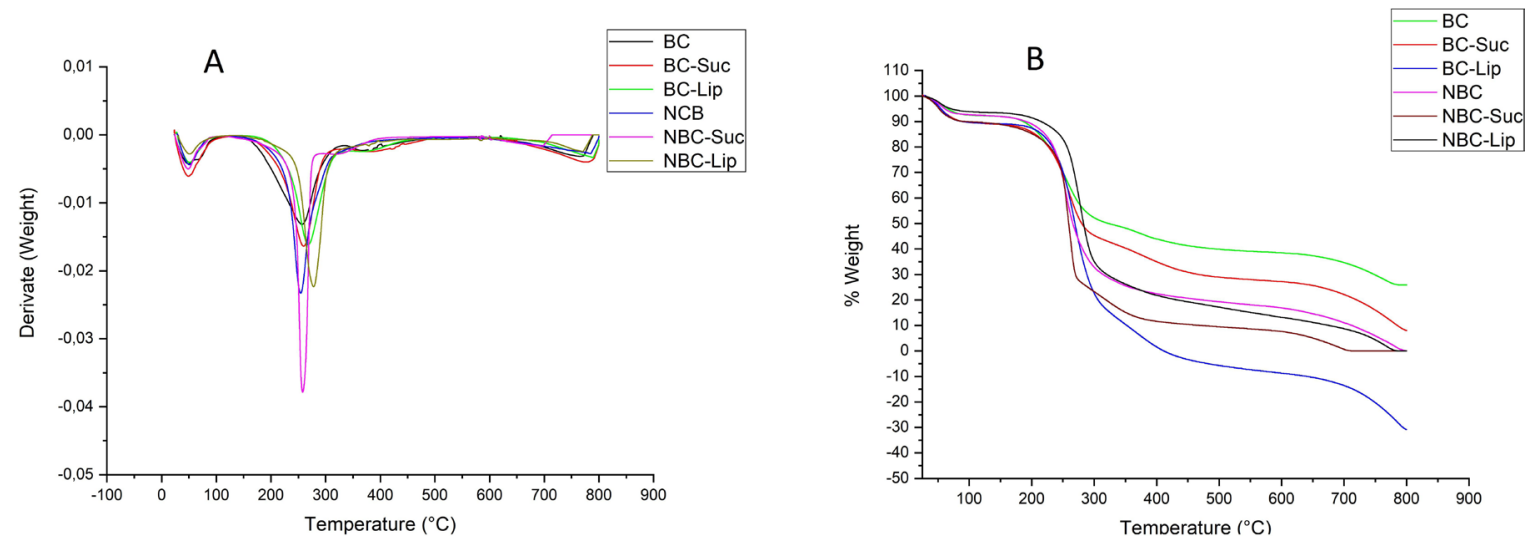

Figure 6. TGA curve of the cellulose membrane and the native, succinylated and immobilized lipase (a) nanocellulose; DTG curve of cellulose membrane and pristine, succinylated and immobilized lipase (b) nanocellulose. 


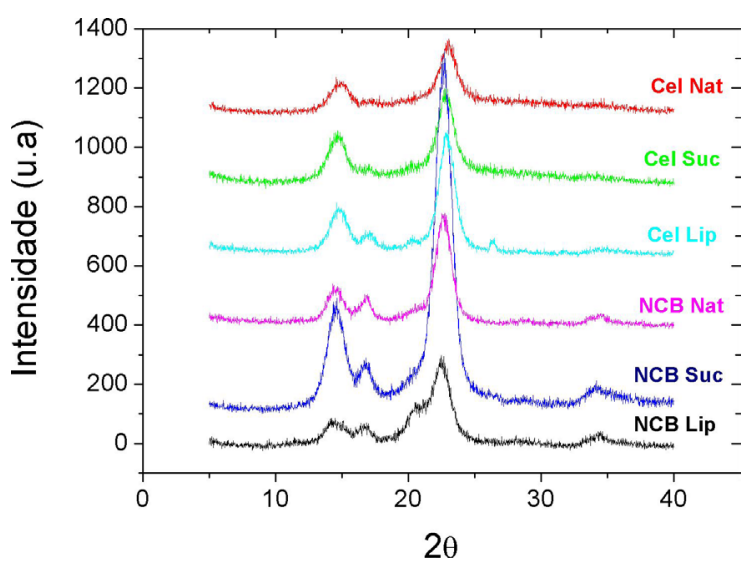

Figure 7. Cellulose DRX and pristine, succinylated and immobilized nanocellulose with lipase.

Table 1. Protein concentration immobilized on bacterial membrane and nanocellulose.

\begin{tabular}{ccc}
\hline & $\begin{array}{c}\mu \mathrm{g} \text { protein/mg cellulose; } \\
\text { cellulose nanocrystals }\end{array}$ & $\begin{array}{c}\text { Weight total de } \\
\text { suport }(\mathrm{mg})\end{array}$ \\
\hline $\boldsymbol{B C}$ & 0 & 18 \\
\hline $\boldsymbol{B C}$-suc & 0 & 17 \\
\hline $\boldsymbol{B} \boldsymbol{C}$-lip & $9,7 \pm 2,90$ & 25 \\
\hline $\boldsymbol{N} \boldsymbol{C B}$ & 0 & 20 \\
\hline $\boldsymbol{N} \boldsymbol{C B}$-suc & 0 & 10 \\
\hline $\boldsymbol{N} \boldsymbol{C B}$-lip & $26,63 \pm 2,70$ & 11 \\
\hline
\end{tabular}

The amount of protein attached to the membrane and nanocellulose was quantified by the Bradford assay, a cheap and recognized method based on the formation of a stable protein complex with the Coomassie Brilliant Blue G-250 reagent, which absorbs light at $595 \mathrm{~nm}$ and can be quantified by UV-Vis spectroscopy to determine the concentration of proteins in a sample using a standard BSA curve ${ }^{29}$. The amount of membrane immobilized proteins and nanocellulose is summarized in Table 1. To ensure that all protein content was quantified, samples were first hydrolyzed with trypsin and then amino acids and peptides could react ${ }^{28,37}$. This strategy has been used, previously, for the quantification of lipases by Wang et al. ${ }^{38}$, and Nicolás, Lassalle, \& Ferreira, $2017^{39}$.

Since the morphological changes and the colorimetric assay show that the protein is attached to the celluloses networks, we proceeded to quantify its lipolytic activity by measuring ${ }^{1} \mathrm{H}$ NMR signals before and after hydrolysis, using soy oil as substrate ${ }^{27}$. The ratio between the glycerol signals at $4.32-4.1 \mathrm{ppm}\left(-\mathrm{CH}_{2}-\right)$, and the $\alpha$-carbonyl methylene hydrogens at $2.35-2.2 \mathrm{ppm}$ was $\sim 4: 6$ for soy oil $(98 \%$ triglycerides) before enzymolysis. After $72 \mathrm{~h}$ of enzymatic activity the amount of triglycerides measured by ${ }^{1} \mathrm{H} \mathrm{nmr}$ was $72.76 \%$ for the free lipase, $69.87 \%$ for lipase-membrane (BC-lip) and $73.5 \%$ for lipase-nanocellulose (NCB-lip). This indicates that the enzyme continued to exert its catalytic activity after immobilization.

The suspension stability of nanocellulose is widely described $^{31,40}$, due to the electrostatic, hydrophobic and Van der Waals interactions between the particles, since of its negative charge due to the $\mathrm{SO}_{4}^{2-}$ groups given during hydrolysis. The stability study of the nanocellulose evaluates the physical properties during a certain storage period. The Figure 8 shows photographs of nanoparticle suspensions of NCB, NCB-suc and NCB-lip at time intervals. In order to obtain values that represents more precisely the nanoparticle comportment in water suspension, the light absorption at $270 \mathrm{~nm}$ was measured using a dedicated UV/Vis spectrometer without remove samples between measurements. The decrease in optical density is often due to the fact that these interactions become weaker with larger particles ${ }^{31,35}$.

The membrane produced at the top of the culture medium by Komagataeibacter hansenni, named bacterial cellulose, is categorized as nanocellulose, taking into account the arrange of the microfibrils with dimensions that reflects its crystalline size and shape ${ }^{41}$ due to the nanometric arrangement of hydrogen linkages. The properties that these tiny-scaled structures engender are huge, increasing thermal stability in comparison to other lower organized glucans $\mathrm{s}^{42}$ and remaining as a membrane despite the chemical processes to which it was exposed.

The chemical reactions to which celluloses was exposed doesn't change in great extension the shape and crystallinity, beside the C-6 preferable linkages on amorphous regions alters the twist of anhydroglucose ${ }^{22}$, that eventually change the crystallinity index. The membrane samples, except for $\mathrm{BC}$-suc, presents the typical high $\mathrm{I}_{\mathrm{C}}$ even for BC-lip, it reduces that this material can be used with the same good physical performance in terms of mechanical resistance, reinforced by the thermal profile obtained.

The process chosen to produce nanocellulose was properly carried out, with an average size, shape, and aspect ratio similar to the ones obtained by other authors. The crystallinity index, suspension stability and thermal characteristics educes that the material that was produced can be used as nanocellulose.

The evidence that the protein was successfully linked to the tested celluloses, as membranes and nanoparticulates, was given by FTIR and solid-state NMR spectra. The former shows succinic acid covalently bonded to the cellulose and the NMR spectrum shows that the protein is present and still there after washing process with water. The colorimetric assay, for protein content quantification, confirmed the binding of chromophores groups, that absorb in the region of UV-Vis, on lipase linked material ${ }^{43}$.

The Bradford quantification showed that a larger surface area of the nanocellulose immobilizes more protein than the membrane, which was probably covered by lipase on its surface considering the size impediment to protein be internalized under the net of cellulose tridimensional structure ${ }^{44}$. Our results are lower than those obtained by Wang et al. ${ }^{38}$, who were able to link $75 \mu \mathrm{g} \mathrm{mg}^{-1}$ of lipase to the resin. On other hand nanocellulose was stable in suspension and the lipase remained active after the reaction process, which is completely reliable for laboratories with small chemistry preparations.

There are studies in the literature that describes the use of immobilized lipase in several applications, as Zaitsev and cols. shows in his review work, that immobilized lipase is an important tool for the field of biotechnology and biomedicine due to its high stability, easy separation and in order to 

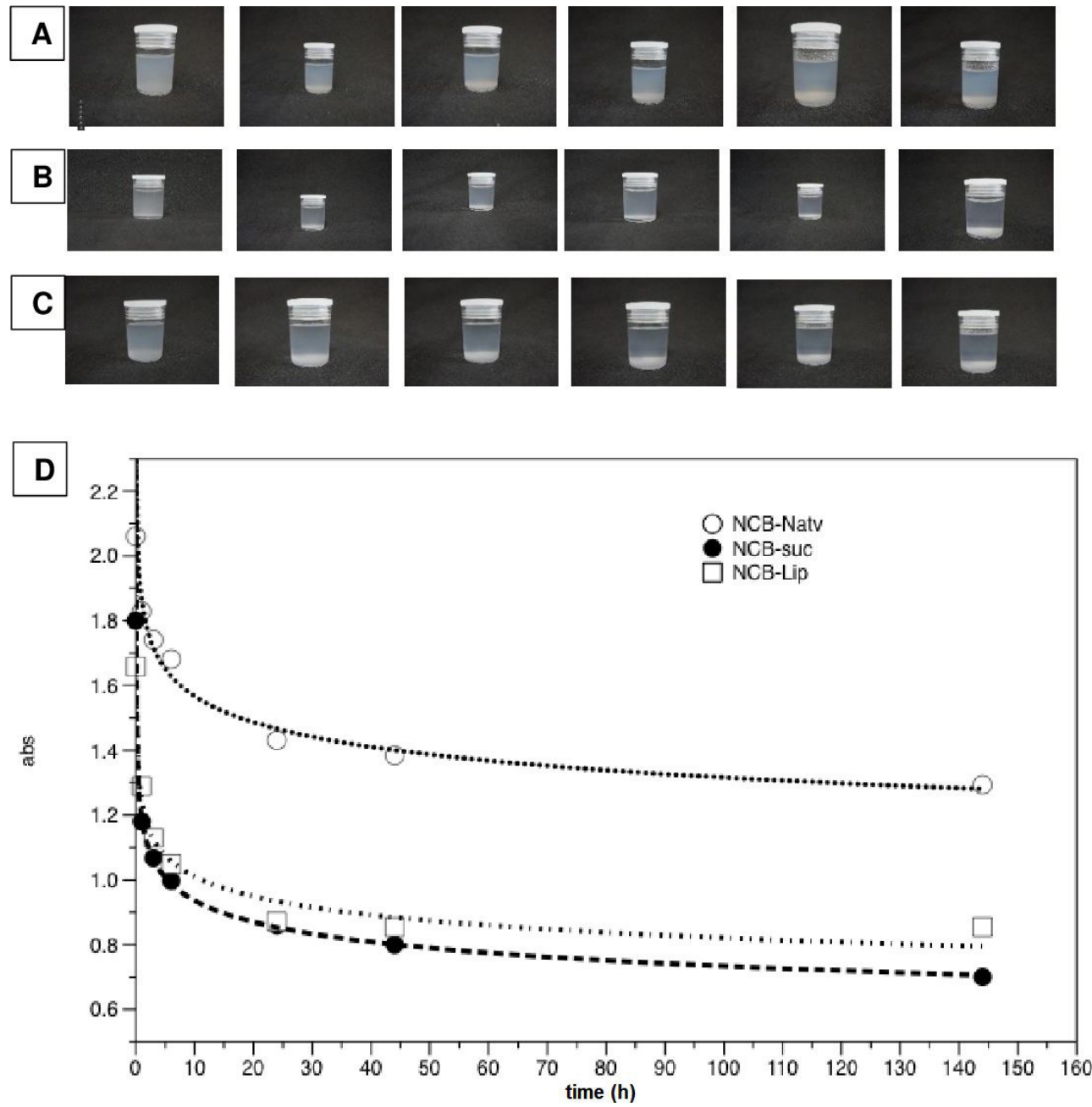

Figure 8. Photographs of suspensions in relation to time (1h, 3h, 6h, 24h, 144h). A: NCB. B: NCB-Suc. C: NCB-Lip.

obtaining an enzyme that can be reused ${ }^{45}$. Is a contemporary issue to be explored as method of functionalization, as done Otari and cols., 2020, that immobilized the lipase in rice straw magnetized with oxide iron, in aim to apply it in reactions in polar environments ${ }^{46}$.

Such as the work of Nady and cols. that had immobilized lipase in sodium titanate nanotubes, and evaluated the production of fatty acids (FAME) for application in cosmetics, such as, lotions, moisturizes and creams ${ }^{47}$.

\section{Conclusions}

The succinilation strategy developed by Ribeiro-Viana and $\operatorname{cols}^{22}$. to link functional proteins shown that was an efficient method for the immobilization of lipase. Not only the persistence of lipase on the cellulose membrane and nanocellulose was widely shown, but the results also demonstrate that the lipolytic activity remains.

The cellulose nanoparticles had a higher crystallinity in relation to the membranes, and showed good stability when in aqueous suspension, even after receive the lipase. It opens the perspective to its use as source material for fields as cosmetics, biochemical sensors.

\section{Acknowledgements}

The authors would like to thank the financial support from CNPq-National Counsel of Technological and Scientific Development (447861/2014-0, and 479992/2013-4) and Araucaria Foundation. Authors would also like to thanks to UEL facilities at Multiuser Laboratories Center (CMLP-UEL FINEP) where X-ray, TGA, FT-IR, NMR and Microscopy analysis where carried out, and specially the Spectroscopy Laboratory at the Universidade Estadual de Londrina (SPECUEL-CT INFRA 2009-01.10.0534.01)

\section{References}

1. French AD. Glucose, not cellobiose, is the repeating unit of cellulose and why that is important. Cellulose. 2017;24(11):4605-9.

2. Fu L, Zhang J, Guang Y. Present status and application BC for skin tissue repair. Carbohydr Polym. 2013;92:1432-42.

3. Donini ÍAN, Salvi DTBD, Fukumoto FK, Lustri WR, Barud HS, Marchetto R, et al. Biossíntese e recentes avanços na produção de celulose bacteriana. Eclét Quím. 2010;35(4):165-78.

4. Kudlicka K, Brown RM Jr. Cellulose biosynthesis in higher plants. Acta Soc Bot Pol. 2014;65(1-2):17-24. 
5. Nechyporchuk O, Belgacem NM, Bras J. Production of cellulose nanofibrils: a revies of recent advances. Ind Crops Prod. 2016;93:2.

6. García A, Gandini A, Labidi J, Belgacem N, Bras J. Industrial and crop wastes: a new source for nanocellulose biorefinery. Ind Crops Prod. 2016;93:26-38.

7. Lin N, Dufresne A. Nanocellulose in biomedicine: current status and future prospect. Eur Polym J. 2014;59:302-25.

8. Elazzouzi-Hafraoui S, Nishiyama Y, Putaux JL, Heux L, Dubreuil F, Rochas C. The shape and size distribution of crystalline nanoparticles prepared by acid hydrolysis of native cellulose. Biomacromolecules. 2008;9(1):57-65.

9. Dai L, Cheng T, Duan C, Zhao W, Zhang W, Zou X, et al. 3D printing using plant-derived cellulose and its derivatives: a review. Carbohydr Polym. 2019;203:71-86.

10. Heggset EB, Chinga-Carrasco G, Syverud K. Temperature stability of nanocellulose dispersions. Carbohydr Polym. 2017; $157: 114-21$

11. Jackson JK, Letchford K, Wasserman BZ, Ye L, Hamad WY, Burt HM. The use of nanocrystalline cellulose for the binding and controlled release of drugs. Int J Nanomedicine. 2011;6:321-30.

12. Modulevsky DJ, Cuerrier CM, Pelling AE. Biocompatibility of subcutaneously implanted plant-derived cellulose biomaterials. PLoS One. 2016;11(6):e0157894.

13. Liu Y, Chen JY. Enzyme immobilization on cellulose matrixes. J Bioact Compat Polym. 2016;31(6):553-67.

14. Pinkert A, Marsh KN, Pang S, Staiger MP. Ionic liquids and their interaction with cellulose. Chem Rev. 2009;109(12):6712-28.

15. Wu S-C, Wu S-M, Su F-M. Novel process for immobilizing an enzyme on a bacterial cellulose membrane through repeated absorption. J Chem Technol Biotechnol. 2017;92(1):109-14.

16. Ansorge-Schumacher MB, Thum O. Immobilised lipases in the cosmetics industry. Chem Soc Rev. 2013;42(15):6475.

17. Malar CG, Seenuvasan M, Kumar KS. Basic study on lipaseimmobilized magnetic nanoparticles. Nanotechnol. Environ. Eng. 2019;4(1):1-6.

18. Li K, Fan Y, He Y, Zeng L, Han X, Yan Y. Burkholderia cepacia lipase immobilized on heterofunctional magnetic nanoparticles and its application in biodiesel synthesis. Sci Rep. 2017;7(1):16473.

19. Girelli AM, Salvagni L, Tarola AM. Use of lipase immobilized on celluse support for cleaning aged oil layers. J Braz Chem Soc. 2012;23:585-92.

20. Kim SR, Abbott NL. Manipulation of the orientational response of liquid crystals to proteins specifically bound to covalently immobilized and mechanically sheared films of functionalized bovine serum albumin. Langmuir. 2002;18(13):5269-76.

21. Bilal M, Iqbal HMN, Guo S, Hu H, Wang W, Zhang X. Stateof-the-art protein engineering approaches using biological macromolecules: A review from immobilization to implementation view point. Int J Biol Macromol. 2018;108:893-901.

22. Ribeiro-Viana RM, Faria-Tischer PCS, Tischer CA. Preparation of succinylated cellulose membranes for functionalization purposes. Carbohydr Polym. 2016;148:21-8.

23. Yuan H, Chen L, Hong FF, Zhu M. Evaluation of nanocellulose carriers produced by four different bacterial strains for laccase immobilization. Carbohydr Polym. 2018;196:457-64.

24. Uth C, Zielonka S, Hörner S, Rasche N, Plog A, Orelma $\mathrm{H}$, et al. A chemoenzymatic approach to protein immobilization onto crystalline cellulose nanoscaffolds. Angew Chem Int Ed. 2014;53:12618-23.

25. Giese M, Blusch LK, Khan MK, MacLachlan MJ. Functional materials from cellulose-derived liquid-crystal templates. Angew Chem Int Ed. 2015;54(10):2888-910.

26. Goelzer FDE, Faria-Tischer PCS, Vitorino JC, Sierakowski MR, Tischer CA. Production and characterization of nanospheres of bacterial cellulose from Acetobacter xylinum from processed rice bark. Mater Sci Eng C. 2009;29(2):546-51.
27. Silva HR, Prete CEC, Zambrano F, de Mello VH, Tischer CA, Andrade DS. Combining glucose and sodium acetate improves the growth of Neochloris oleoabundans under mixotrophic conditions. AMB Express. 2016;6(1):10.

28. Atacan K, Çakiroğlu B, Özacar M. Improvement of the stability and activity of immobilized trypsin on modified $\mathrm{Fe} 3 \mathrm{O} 4$ magnetic nanoparticles for hydrolysis of bovine serum albumin and its application in the bovine milk. Food Chem. 2016;212:460-8.

29. Bradford MM. A rapid and sensitive method for the quantitation microgram quantities of protein utilizing the principle of protein-dye binding. Anal Biochem. 1976;72:248-54.

30. de Oliveira SA, da Silva BC, Riegel-Vidotti IC, Urbano A, de Sousa Faria-Tischer PC, Tischer CA. Production and characterization of bacterial cellulose membranes with hyaluronic acid from chicken comb. Int J Biol Macromol. 2017;97:642-53.

31. Niu F, Li M, Huang Q, Zhang X, Pan W, Yang J, et al. The characteristic and dispersion stability of nanocellulose produced by mixed acid hydrolysis and ultrasonic assistance. Carbohydr Polym. 2017;165:197-204.

32. Dubey S, Sharma RK, Agarwal P, Singh J, Sinha N, Singh RP. From rotten grapes to industrial exploitation : komagataeibacter europaeus SGP37, a micro-factory for macroscale production of bacterial nanocellulose. Int J Biol Macromol. 2017;96:52-60.

33. Pandey JK, Kim CS, Chu WS, Choi WY, Ahn SH, Lee CS. Preparation and structural evaluation of nano reinforced composites from cellulose whiskers of grass and biodegradable polymer matrix. J Compos Mater. 2012;46(6):653-63.

34. Kunaver M, Anžlovar A, Žagar E. The fast and effective isolation of nanocellulose from selected cellulosic feedstocks. Carbohydr Polym. 2016;148:251-8.

35. Geiger T, Zimmermann T, Sixta H. The chemical-free production of nanocelluloses from microcrystalline cellulose and their use as Pickering emulsion stabilizer. Carbohydr Polym. 2017;178:48-56.

36. Funari CS, Castro-Gamboa I, Cavalheiro AJ, Bolzani VS. Metabolômica, uma abordagem otimizada para exploração da biodiversidade brasileira: estado da arte, perspectivas e desafios. Quim Nova. 2013;36:1605-9.

37. Atacan K, Çakıroğlu B, Özacar M. Covalent immobilization of trypsin onto modified magnetite nanoparticles and its application for casein digestion. Int J Biol Macromol. 2017;97:148-55.

38. Wang X, Li D, Qu M, Durrani R, Yang B, Wang Y. Immobilized MAS1 lipase showed high esterification activity in the production of triacylglycerols with n-3 polyunsaturated fatty acids. Food Chem. 2017;216:260-7.

39. Nicolás P, Lassalle VL, Ferreira ML. Quantification of immobilized Candida antarctica lipase B (CALB) using ICP-AES combined with Bradford method. Enzyme Microb Technol. 2017;97:97-103.

40. Jesus Silva D, D'Almeida MLO. Nanocristais de celulose. O Pap. 2009;70:34-52.

41. Börjesson M, Westman G. Crystalline nanocellulose: preparation, modification, and properties. In Poletto M, editor. Cellulose: fundamental aspects and current trends. London: IntechOpen; 2015.

42. Lin N, Huang J, Dufresne A. Preparation, properties and applications of polysaccharide nanocrystals in advanced functional nanomaterials: a review. Nanoscale. 2012;4(11):3274-94.

43. Silva RD, Sierakowski MR, Bassani HP, Zawadzki SF, Pirich CL, Ono L, et al. Hydrophilicity improvement of mercerized bacterial cellulose films by polyethylene glycol graft. Int J Biol Macromol. 2016;86:599-605.

44. Lima LR, Santos DB, Santos MV, Barud HS, Henrique MA, Pasquini D, et al. Nanocristais de celulose a partir de celulose bacteriana. Quim Nova. 2015;38(9):1-8.

45. Zaitsev SY, Savina AA, Zaitsev IS. Biochemical aspects of lipase immobilization at polysaccharides for biotechnology. Adv Colloid Interface Sci. 2019;272:102016. 
46. Otari SV, Patel SKS, Kalia VC, Lee JK. One-step hydrothermal synthesis of magnetic rice straw for effective lipase immobilization and its application in esterification reaction. Bioresour Technol. 2020;302:122887.
47. Nady D, Zaki AH, Raslan M, Hozayen W. Enhancement of microbial lipase activity via immobilization over sodium titanate nanotubes for fatty acid methyl esters production. Int J Biol Macromol. 2020;146:1169-79. 